\title{
Interleukin 2 modulates ion secretion and cell proliferation in cultured human small intestinal enterocytes
}

\author{
E V O’Loughlin, G P Pang, R Noltorp, C Koina, R Batey, R Clancy
}

\begin{abstract}
Aims-To determine if interleukin 2 (IL-2) alters epithelial transport and barrier function in cultured human small intestinal enterocytes.

Methods-Confluent monolayers of small intestinal cells derived from duodenal biopsies were treated with IL-2 0.2-50 U/ml for 24 hours prior to study. Transport measurements were performed under short circuited conditions in Ussing chambers, with and without the secretagogues forskolin and 3-isobutyl-1-methyl xanthine (IBMX). Serosal to mucosal flux of ${ }^{3}[\mathrm{H}]$ mannitol (permeability) and ${ }^{3}[\mathrm{H}]$ thymidine uptake (proliferation) were measured. IL-2 receptor and cystic fibrosis transmembrane conductance regulator (CFTR) mRNA were identified using reverse transcription-polymerase chain reaction (RT-PCR).
\end{abstract}

Results-IL-2 did not alter baseline electrical parameters but caused a significant increase in cAMP dependent chloride secretion. The effect was mediated by the IL-2 receptor and paralleled a rapid increase in tyrosine phosphorylation, janus kinase 1, and signal transducers and activators of transcription (STATs) 1, 3, and 5. IL-2 significantly increased proliferation but at a lower dose than observed for enhanced secretion but did not alter permeability. IL-2 receptor $\beta$ and $\gamma c$ chains and CFTR mRNA were identified by RT-PCR.

Conclusions-IL-2 treatment enhances cAMP stimulated chloride secretion and cellular proliferation in a human small intestinal cell line expressing a functional IL-2 receptor.

(Gut 2001;49:636-643)

Keywords: interleukin 2; ion secretion; cell proliferation; enterocytes; small intestine

The ability to regulate epithelial fluid and electrolyte secretion provides a potent defence mechanism to protect the mammalian gastrointestinal tract against pathogenic organisms, noxious dietary antigen, and parasitic infestation. Secretion of fluid and electrolytes, while contributing to diarrhoea, enables the host to flush the lumen in an attempt to expel potential invaders. In recent years, it has become apparent that the mucosal immune system plays an important role in regulating fluid and electrolyte secretion as an integrated component of mucosal host defence. ${ }^{1}$

Several mucosal immunocytes have the ability to regulate epithelial transport including mast cells, ${ }^{2-6}$ polymorphonuclear neutrophils, ${ }^{7-10}$ and peripheral blood monocytes $^{11}$ by releasing a range of secretagogues such as eicosanoids, histamine, serotonin, and 5'AMP. Lymphocytes are also important mediators of inflammation in the gastrointestinal tract but little is known about their role in modulating epithelial function. Isolated intraepithelial lymphocytes from mice intestine stimulate enterocyte proliferation when cocultured with small intestinal enterocytes. ${ }^{12}$ Moreover, activation of mucosal lymphocytes in the lamina propria of fetal small intestine grown in organ culture stimulates crypt proliferation and villus atrophy. ${ }^{13}$ Few studies have addressed the question of whether lymphocytes modulate epithelial transport. McKay and colleagues ${ }^{11}$ cocultured T84 cells with circulating human lymphocytes but found that the activated lymphocytes did not alter ion transport or barrier function in epithelial cells. However, given their role in many inflammatory disorders of the intestine, it is conceivable that lymphocytes could modulate epithelial transport of fluid and electrolytes.

Interleukin 2 (IL-2) is an important cytokine secreted by lymphocytes and plays a major role in stimulating proliferation of mucosal lymphocytes, natural killer cells, and macrophages. Until recently, its role was thought to be restricted to modulating the growth of immunocytes. However, functional IL-2 receptors have been identified in several intestinal cell culture lines, in rat small intestinal enterocytes, and in human colonocytes, ${ }^{14}{ }^{15}$ implying a physiological role for IL-2 in modulating epithelial function.

We have previously described cultured human small intestinal cell lines derived from endoscopic biopsies. ${ }^{16}$ One such line, BN, grows in a polarised monolayer, morphologically resembles immature small intestinal crypt

Abbreviations used in this paper: CFTR, cystic fibrosis transmembrane conductance regulator; G, conductance; IBMX, 3-isobutyl-1-methyl xanthine; IL, interleukin; IL-2R, interleukin 2 receptor; DMEM,

Dulbecco's modified Eagle's medium; Isc, short circuit current; JAK, janus kinases; PD, potential difference; J, flux; STAT, signal transducers and activators of transcription; PBS, phosphate buffered saline; RT-PCR, reverse transcription-polymerase chain reaction; GAPDH, glyceraldehyde-3-phosphate dehydrogenase. 
cells with a rudimentary brush border expressing low levels of sucrase, and exhibits vectorial transport. When studied under voltage clamp conditions in Ussing chambers, monolayer resistance varies from 30 to $200 \Omega$ and addition of secretagogue to the bathing solutions stimulates an increase in apical chloride secretion. Preliminary studies coincubating the monolayers with isolated tonsillar lymphocytes resulted in an increase in secretagogue stimulated secretion (unpublished observations). We postulated that factors such as IL-2 required to propagate the lymphocytes may have been responsible for this effect.

The aims of this study were to examine further the effect of IL-2 on epithelial function. Specifically, we studied the effect of IL-2 on ion secretion, cellular proliferation, and epithelial permeability utilising a human small intestinal cell culture line, $\mathrm{BN}^{16}$.

\section{Methods}

CELL CULTURES AND IL-2 TREATMENT

Clones of human small intestinal enterocytes (BN) were obtained from a single patient as previously described. ${ }^{16}$ Cells were grown as monolayers in Dulbecco's modified Eagle's medium (DMEM) containing 10\% fetal calf serum, L-glutamine, and antibiotics. Cells were split after treatment with trypsin-versene and cultured on permeable supports (Falcon cell culture inserts, $4 \mu \mathrm{m}$ pore and $24.5 \mathrm{~mm}$ diameter; Becton Dickinson, Franklin Lakes, New Jersey, USA) in a six well culture plate for 48 hours. After reaching confluence, the medium was removed from the monolayers and replaced with fresh medium containing rIL-2 at doses ranging from 0.2 to $50 \mathrm{U} / \mathrm{ml}$ and in some experiments rIL-15 $0.5-5 \mathrm{ng} / \mathrm{ml}$ (doses in U or $\mathrm{ng}$ as per the manufacturers' instructions). Each experiment was performed with paired control monolayers which contained medium alone. The cells were grown for a further 24 hours at which time confluence of the monolayers was verified under an inverted microscope and monolayers were then studied.

IN VITRO TRANSPORT STUDIES

Confluent monolayers were mounted in Ussing chambers in quadruplicate and studied as previously described. ${ }^{16}$ Each chamber exposed $1.12 \mathrm{~cm}^{2}$ surface area to apical and basolateral reservoirs containing $10 \mathrm{ml}$ of Krebs buffer at $37^{\circ} \mathrm{C}, \mathrm{pH} 7.4$, containing (mmol/1): $\mathrm{Na}^{+} 140$; $\mathrm{Cl}^{-} 127.5 ; \mathrm{HCO}_{3}^{-} 25 ; \mathrm{K}^{+} 10 ; \mathrm{Ca}^{2+} 1.25 ; \mathrm{Mg}^{2+}$ $1.1 ; \mathrm{H}_{2} \mathrm{PO}_{4}^{-} 2$ with mannitol $5 \mathrm{mmol}$ on the mucosal side and glucose $5 \mathrm{mmol}$ on the serosal side. Buffers were oxygenated with $95 \% \mathrm{O}_{2}$ and $5 \% \mathrm{CO}_{2}$ and the buffers circulated by gas lift. Spontaneous transepithelial potential difference (PD, millivolts $(\mathrm{mV})$ ) was determined and the monolayer clamped at zero voltage by introducing a continuous short circuit current (Isc microamperes $(\mu \mathrm{Amp})$ ) by automatic voltage clamp (DVC 1000; World Precision Instruments, New Haven, Connecticut, USA). Open circuit PD was measured for 3-5 seconds every 10 minutes and conductance $(G$, milliSiemens $(\mathrm{mS})$ ) determined by voltage clamping the monolayer at $10 \mathrm{mV}$ and measuring the resultant Isc. $\mathrm{G}$ was calculated from $\triangle \mathrm{PD}$ and $\Delta$ Isc using Ohm's law. Monolayers were discarded when $\mathrm{G}$ was $>15 \mathrm{mS} / \mathrm{cm}^{2}$. Isc was continuously recorded by pen chart recorder and electrical parameters recorded at 10 minute intervals after an initial 10 minute baseline equilibration period.

\section{Secretagogue stimulated Isc}

Electrical parameters were measured during a basal period followed by a second period when the secretagogues forskolin $10^{-5} \mathrm{M}$ and IBMX (3-isobutyl-1-methyl xanthine) $3 \times 10^{-4} \mathrm{M}$ were added together to both sides of the monolayers. ${ }^{17}$ Change in Isc ( $\Delta \mathrm{Isc}$ ) was determined from the peak increase after secretagogue addition. Time course experiments were performed to determine the time of onset of action of IL-2. Cells were incubated with IL-2 $5 \mathrm{U} / \mathrm{ml}$ for 30 minutes, two hours, and 24 hours. Initial experiments indicated that 24 hour incubation of the cell culture with $5 \mathrm{U} / \mathrm{ml} \mathrm{IL}-2$ induced the maximum increase in secretagogue stimulated Isc. This time point was used in subsequent experiments. Experiments were repeated in chloride free buffer in which chloride salts were substituted with gluconate salts. ${ }^{18}$ To determine if IL-2 enhancement of secretagogue stimulated secretion was mediated via the IL-2 receptor, cells were incubated with antiCD122 (anti-IL-2R $\beta$ chain antibody; Pharmingen, San Diego, California, USA) 0.5 $\mu \mathrm{g} / \mathrm{ml}$, added six hours after seeding the cells. IL-2 $5 \mathrm{U} / \mathrm{ml}$ was added at 24 hours and studies performed at 48 hours post seeding. Treatment of monolayers with a mouse IgG2, anti-IL-4 $\beta$ chain antibody (an irrelevant antibody of similar isotype) had no effect on baseline electrical parameters or secretagogue stimulated Isc.

The specificity of the IL-2 effect on secretagogue induced secretion was examined in experiments where cells were treated with IL-15 $(0.5-5 \mathrm{ng} / \mathrm{ml})$ using the same protocol as for IL-2. IL-15 receptor shares common $\beta$ and $\gamma$ chains with IL-2R and induces similar biological effects. ${ }^{19}$

\section{Epithelial permeability}

Monolayer permeability was assessed by measuring serosal to mucosal flux of ${ }^{3}[\mathrm{H}]$ mannitol. Isotope $(10 \mu \mathrm{Ci})$ was added to the basolateral side and allowed to equilibrate for 10 minutes. Flux measurements were determined using standard techniques as previously described ${ }^{20}$ during three 10 minute and one overall 30 minute period. Serosal to mucosal flux $\left(\mathrm{J}_{\mathrm{s}-\mathrm{m}}\right)$ was calculated and data are expressed as $\mu \mathrm{mol} /$ $\mathrm{cm}^{2} / \mathrm{h}$.

THYMIDINE INCORPORATION INTO BN CELLS $\mathrm{BN}$ cells from monolayer cultures were seeded in $100 \mu \mathrm{l}$ aliquots at 5000-10 000 cells/well in DMEM $/ 10 \%$ fetal calf serum into wells of a 96 well flat bottomed microtitre plate. Medium alone $(100 \mu \mathrm{l})$ or medium containing IL-2 $(0.2-40 \mathrm{U} / \mathrm{ml})$ was added in triplicate into the wells. After 24 hours of incubation, the cultures were pulsed with ${ }^{3}[\mathrm{H}]$ thymidine, $1 \mu \mathrm{Ci} /$ well for the final six hours before harvesting and counting in a liquid scintillation counter. ${ }^{21}$ Results 
Table 1 Polymerase chain reaction primer pairs used for detection of $\alpha, \beta$, and $\gamma c$ chains of interleukin 2 receptor (IL-2R), cystic fibrosis transmembrane conductance regulator (CFTR), and glyceraldehyde-3-phosphate dehydrogenase (GAPDH) genes

\begin{tabular}{ll}
\hline IL-2R $\alpha$ & \\
Sense & 5' TCTTCCCATCCCACATCCTC \\
Antisense & 3' TCTGCGGAAACCTCTCTTGC \\
IL2-R $\beta$ & \\
Sense & 5' GGCTTTTGGCTTCATCATCT \\
Antisense & 3' CTTGTCCCTCTCCAGCACTT \\
IL2-R $\gamma$ & \\
Sense & 5' ACGGGAACCCAGGAGACAGG \\
Antisense & 3' AGCGGCTCCGAACACGAAAC \\
GAPDH & 5' ACCACAGTCCATGCCATCAC \\
Sense & 3' ATGTCGTTGTCCCACCACCT \\
Antisense & \\
CFTR & 5' CAGAACTGAAACTGACTCGG (exon 7-5') \\
Sense & 3' GTTGGCATGCTTTGATGACGCTTC (exon 10-3') \\
Antisense &
\end{tabular}

Table 2 Electrical parameters in control and interlekin 2 (IL-2) treated BN monolayers

\begin{tabular}{llll}
\hline & $P D(\mathrm{mV})$ & Isc $\left(\mu \mathrm{Amp} / \mathrm{cm}^{2}\right)$ & $G\left(\mathrm{mS} / \mathrm{cm}^{2}\right)$ \\
\hline Control & $-0.29(0.06)$ & $0.59(0.17)$ & $4.29(0.35)$ \\
IL-2 $(5 \mathrm{U} / \mathrm{ml})$ & $-0.16(0.05)$ & $0.79(0.20)$ & $4.38(0.32)$ \\
$\mathrm{p}$ & NS & NS & NS
\end{tabular}

Values are mean (SEM) of 32 paired monolayers. Means were compared using the paired Student's $t$ test.

$\mathrm{PD}$, potential difference; Isc, short circuit current; G, conductance.

are reported as per cent of non-IL-2 treated controls.

RT-PCR DETECTION OF IL-2, IL-15 RECEPTORS, AND CFTR MRNA

Complementary DNA (cDNA) synthesis and amplification using reverse transcriptionpolymerase chain reaction (RT-PCR) have been previously described. ${ }^{16}$ The PCR primer pairs for detection of $\alpha, \beta$, and $\gamma c$ chains of the IL-2 receptor, cystic fibrosis transmembrane conductance regulator (CFTR), and glyceraldehyde-3-phosphate dehydrogenase (GAPDH) genes, used according to published sequences, are shown in table $1 .^{15} 2223$

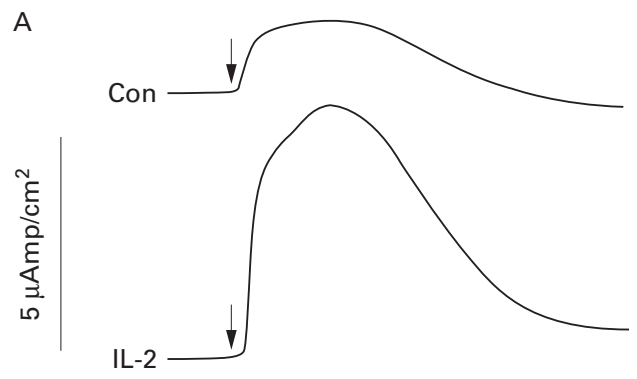

B

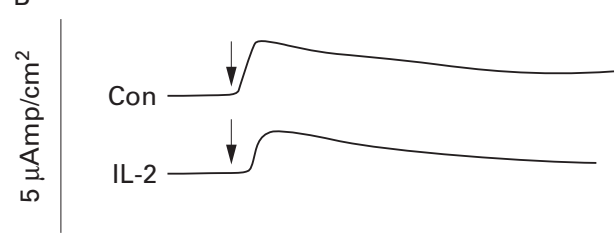

IMMUNOBLOT DETECTION OF TYROSINE PHOSPHORYLATED AND JAK AND STAT PROTEINS $\mathrm{BN}$ cells were grown in transwells with six well cluster plates (Becton Dickinson) for 36 hours in DMEM containing $10 \%$ fetal calf serum. The cells were then washed in phosphate buffered saline (PBS) and recultured in serum free medium with $5 \mathrm{U}$ of IL-2 for various times. At each time point, $300 \mu \mathrm{l}$ of cell lysis buffer (250 $\mathrm{mM}$ Tris $\mathrm{HCl}, \mathrm{pH} 6.8,4 \%$ sodium dodecyl sulphate, $10 \%$ glycerol, $2 \%$ 2-mercaptoethanol, $1 \mathrm{mM}$ phenylmethylsulphonyl fluoride) heated at $95^{\circ} \mathrm{C}$ for five minutes was added to the insert. The lysate was collected, heated for two minutes, and centrifuged at $5000 \mathrm{rpm}$ for five minutes in a Microfuge. Samples were resolved by sodium dodecyl sulphate-polyacrylamide gel electrophoresis and transferred to Immobilon membranes (Millipore, North Ryde, NSW, Australia). Membrane blots were blocked with $5 \%$ non-fat skim milk at $4^{\circ} \mathrm{C}$ overnight before incubating sequentially with anti-janus kinase 1 (JAK1) (1:1500), anti-signal transducers and activators of transcription (STAT)-1, STAT-3 (1:1000), and STAT-5 (1:250), or antiphosphotyrosine (1:1000) mouse monoclonal antibodies (Santa Cruz Biotechnology, California, USA), biotinylated sheep antimouse IgG (1:1000), and horseradish peroxidase conjugated streptavidin (1:2000) (Amrad Biotech, Melbourne, Australia) according to the manufacturer's instructions. Signals were detected by enhanced chemiluminescence (ECL, Amersham, Piscataway, USA).

ANALYSIS OF DATA

Values are depicted as mean (SEM). Because of the variability of the Isc response to secretagogue in different preparations of $\mathrm{BN}$ cells, the secretagogue stimulated Isc is depicted as per cent increase over paired non-treated control
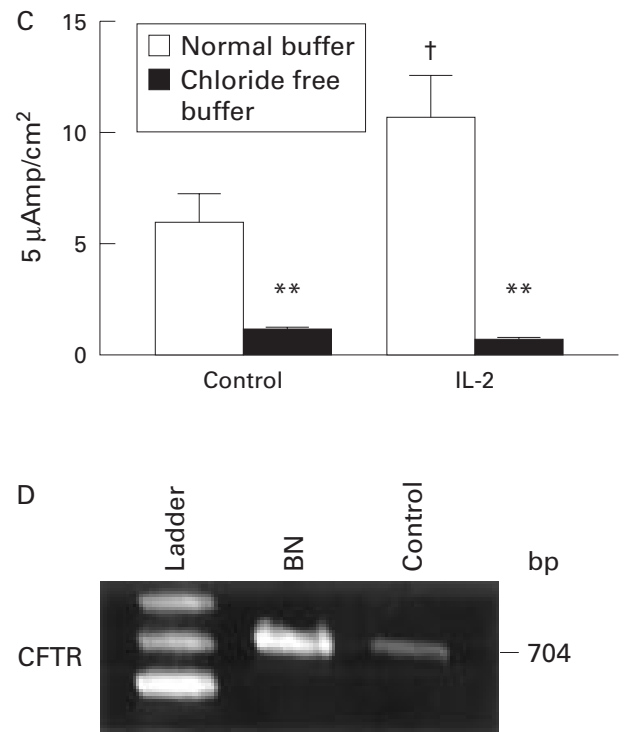

Figure 1 Effect of interleukin 2 (IL-2) on cAMP dependent chloride secretion in BN cells. (A) Representative traces of control (Con) and IL-2 treated monolayers. (B) Representative traces of control and IL-2 treated monolayers in chloride free buffer. (C) Secretagogue stimulated short circuit current (UIsc) in normal buffer and paired monolayers in chloride free buffer ( $n=7-9$ pairs, data are mean (SEM)). (D) Constitutive expression of cystic fibrosis transmembrane conductance regulator (CFTR) $m R N A$ in BN cells and controls (human small intestinal biopsy). Cells depicted in ( $A-C)$ were treated with IL-2 $5 \mathrm{U} / \mathrm{ml}$ for 24 hours prior to the study; secretion, stimulated with 3-isobutyl-1-methyl xanthine (IBMX) $3 \times 10^{-4}$ $M$ and forskolin $10^{-6} \mathrm{M}$ (arrows). bp, base pairs. ${ }^{\star *} p<0.01$ compared with control and $t p<0.02$ compared with respective control period by paired t test. 

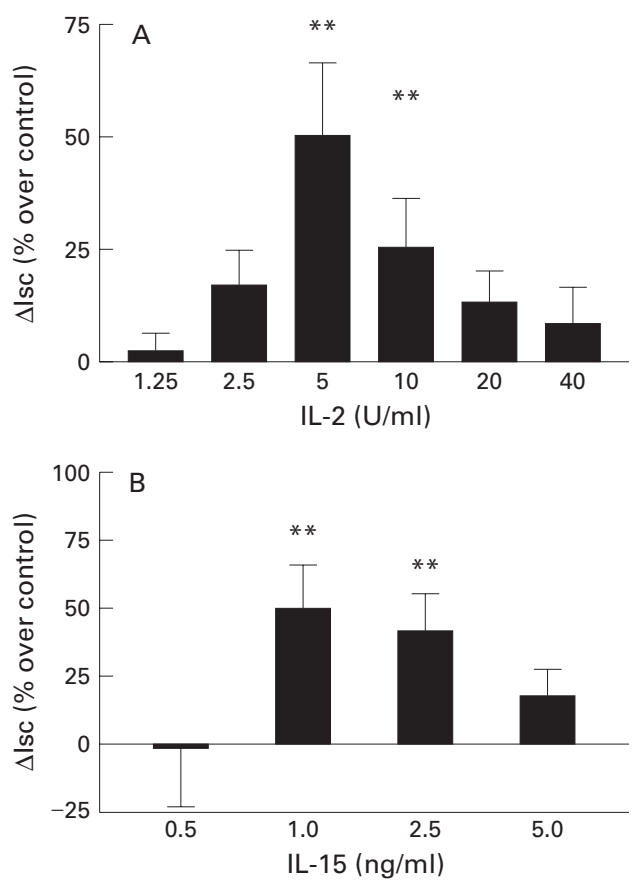

Figure 2 Dose response of $(A)$ interleukin 2 (IL-2) and (B) interleukin 15 (IL-15) secretagogue stimulated short circuit current (Isc). Cells were incubated for 24 hours with either IL-2 or IL-15. Anion secretion was stimulated with forskolin $10^{-5} \mathrm{M}$ and 3-isobutyl-1-methyl xanthine (IBMX) $3 \times 10^{-4}$ M. Data are mean (SEM). Change in Isc (AIsc) is depicted as percentage of paired control monolayer, $n=14-31$ pairs. ${ }^{\star *} p<0.01$ compared with control by paired t test.

values unless otherwise stated. The effect of IL-2 on study parameters was assessed by the paired Student's $t$ test with Bonferroni correction for multiple analyses. The effect of different doses of IL-2 on ${ }^{3}[\mathrm{H}]$ thymidine uptake was assessed using analysis of variance. If differences were significant, means were compared using Dunnett's test for multiple comparisons. $\mathrm{p}<0.05$ was considered significant.

\section{Results}

CHLORIDE SECRETION

IL-2 had no obvious effect on the ability of BN cells to form a confluent monolayer. Baseline electrical parameters are depicted in table 2 for monolayers treated with $5 \mathrm{U} / \mathrm{ml} \mathrm{IL-2,} \mathrm{the} \mathrm{dose}$ which caused greatest enhancement of secretagogue stimulated Isc. Consistent with our previous observations, untreated $\mathrm{BN}$ cells exhibited low PD and Isc compared with other intestinal cells such as T84 cells. ${ }^{24}{ }^{25}$ Twenty four hour treatment with IL-2 caused no change in any baseline electrical parameter. Thus IL-2 treatment had no effect on baseline electrogenic ion transport properties of the cell monolayers.

IL-2 treatment at low doses enhanced the effect of the secretagogues IBMX and forskolin in stimulating Isc. Data are depicted in figs 1 and 2 . BN cells treated with 5 and $10 \mathrm{U} / \mathrm{ml}$ IL-2 exhibited a significant increase in Isc ( $p<0.001$ compared with paired controls). There was slight enhancement of Isc at the lower dose of $2.5 \mathrm{U} / \mathrm{ml}$ and at doses greater than $10 \mathrm{U} / \mathrm{ml}$ but these changes were not statistically significance. Subsequent experiments examining chloride secretion utilised 5 $\mathrm{U} / \mathrm{ml} \mathrm{IL}-2$ treatment.

To determine whether enhancement of secretagogue stimulated secretion was limited to IL-2, experiments were repeated utilising IL-15 and an unrelated interleukin IL-4. IL-15 exhibited a dose dependent enhancement of secretagogue stimulated secretion (fig $2 \mathrm{~B}$ ) in contrast with IL-4 which had no effect (data not shown).

We have previously demonstrated that forskolin stimulated Isc in $\mathrm{BN}$ cells is due largely to chloride secretion as it is inhibited by chloride free buffer and apical addition of the chloride channel blocker diphenylamine-2decarboxylate. ${ }^{16}$ To confirm that IL-2 treatment enhanced chloride secretion in response to forskolin/IBMX, experiments were repeated in chloride free buffer (fig 1C). In this group of experiments, IL-2 significantly increased secretagogue stimulated Isc from 5.96 (1.26) to $10.83(1.88) \mu \mathrm{Amp} / \mathrm{cm}^{2}(\mathrm{n}=7$ pairs; $\mathrm{p}<0.02)$. Removing chloride from the buffer caused a significant reduction in secretagogue stimulated Isc in both control and IL-2 treated monolayers $(p<0.01)$, and inhibited any IL-2 induced enhancement. The data suggest that IL-2 enhances cAMP dependent chloride secretion. This pathway of secretion is mediated by CFTR in the gastrointestinal tract. ${ }^{25}$ Indeed, CFTR mRNA was detected in these cells by RT-PCR (fig 1D) although IL-2 treatment was not found to increase CFTR mRNA at 24 hours. Forskolin/IBMX stimulated Isc $(\Delta \mathrm{Isc})$ not inhibited by chloride free buffers constituted approximately $20-25 \%$ of the total stimulated Isc. This chloride independent $\Delta I s c$ was significantly reduced by IL-2 treatment: $0.83(0.09) \mu \mathrm{Amp} / \mathrm{cm}^{2}$ in IL-2 treated monolayers $v 1.23(0.10)$ in controls; $\mathrm{p}<0.02, \mathrm{n}=13$ pairs) (see fig $1 \mathrm{C}$ ).

The time course of the IL-2 effect on secretion was examined in a separate group of monolayers and the data are depicted in fig 3 . Thirty minutes of exposure of the monolayers to IL-2 induced a slight but non-significant increase in secretagogue stimulated Isc. However, by two hours this had increased further to 36 (6)\% $(p<0.01)$ and remained elevated at 24 hours. In

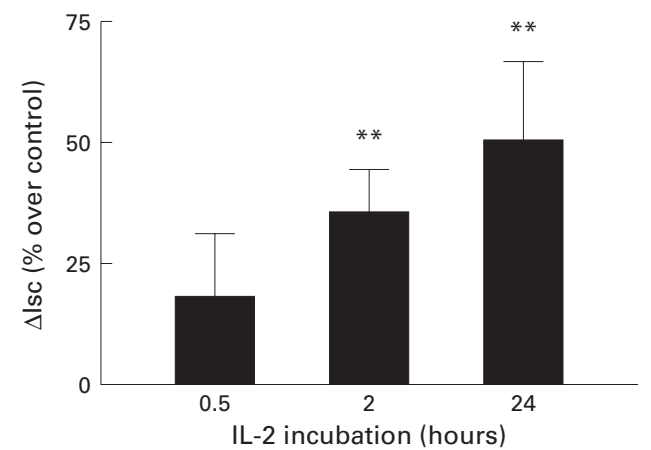

Figure 3 Time course of interleukin 2 (IL-2) effect on secretagogue stimulated short circuit current (Isc). Cells were treated with IL-2 $5 \mathrm{U} / \mathrm{ml}$. Anion secretion was stimulated with forskolin $10^{-5} \mathrm{M}$ and 3-isobutyl-1-methyl xanthine (IBMX) $3 \times 10^{-4} M .{ }^{*} p<0.01$ compared with paired control monolayers. $n=7,14$, and 23 pairs at 0.5, 2, and 24 hours, respectively. 

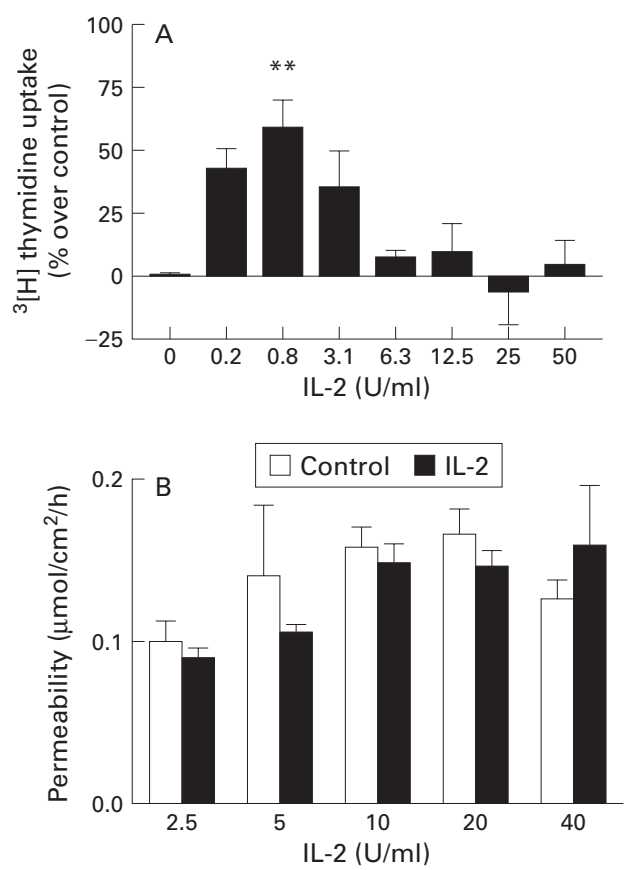

Figure 4 Dose-response of interleukin 2 (IL-2) effect on (A) cellular proliferation and (B) mannitol permeability. In $(A), n=3$ dose-response experiments. ${ }^{\star \star} p<0.01$ compared with untreated monolayers. In (B), mannitol fluxes are serosal to mucosal in $n=13-23$ pairs.

contrast, IL-2 did not cause any significant alteration of electrical conductance at any time point.

The enhanced effect of IL-2 incubation on secretagogue stimulated Isc was inhibited in four of five monolayers pretreated with the IL-2 receptor antibody anti-CD122. Control monolayers, without IL-2 treatment, exhibited an increase in Isc of $6.3(0.4) \mu \mathrm{Amp} / \mathrm{cm}^{2}$ which was not significantly different to IL-2 treated (5

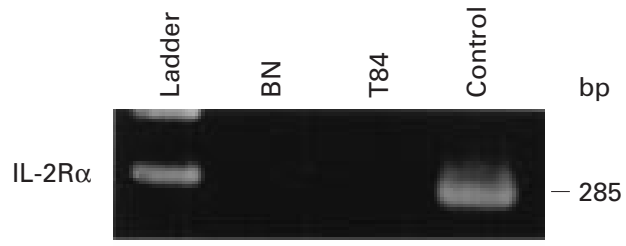

IL-2R $\beta$

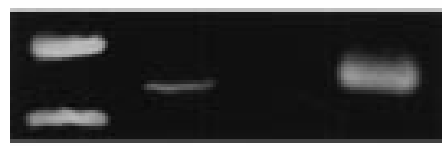

238
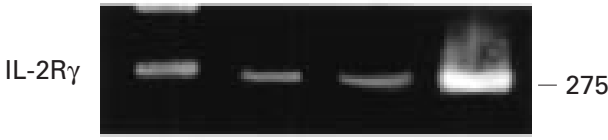

GAPDH

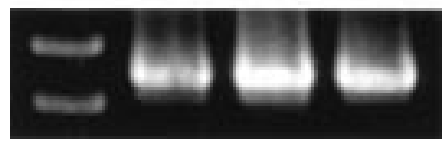

Figure 5 Constitutive expression of interleukin 2 receptor (IL-2R) $\alpha, \beta$, and $\gamma$ chain mRNA genes. Control transcripts were derived from peripheral blood lymphocytes and exhibited all three chains of the receptor. In contrast, $B N$ (small intestinal cells) expressed $\beta$ and $\gamma$ chains, and T84 cells $\gamma$ chain only. bp, base pairs; GAPDH, glyceraldehyde-3-phosphate dehydrogenase.
$\mathrm{U} / \mathrm{ml}, 24$ hours) monolayers which had been pretreated with anti-CD122 antibody (5.6 (1.6) $\mu \mathrm{Amp} / \mathrm{cm}^{2}$ ).

CELL PROLIFERATION

These studies were performed without prior depletion of fetal calf serum from the culture medium. Despite this, IL-2 treatment stimulated cell proliferation at low doses. Treatment with $0.2-3.1 \mathrm{U} / \mathrm{ml}$ caused an increase in ${ }^{3}[\mathrm{H}]$ thymidine incorporation after 18 hours of incubation. However, this increase was only significant at a dose of $0.8 \mathrm{U} / \mathrm{ml}(159$ (11.3)\%; $\mathrm{p}=0.001$ compared with control) (fig $4 \mathrm{~A})$.

MANNITOL PERMEABILITY

Preliminary experiments with $\mathrm{BN}$ cells assessed unidirectional and net fluxes of ${ }^{3}[\mathrm{H}]$ mannitol. Mucosal to serosal flux $\left(\mathrm{J}_{\mathrm{ms}}, 0.165\right.$ $(0.07) \mu \mathrm{mol} / \mathrm{cm}^{2} / \mathrm{h} ; \mathrm{n}=13$ ) was not significantly different to serosal to mucosal flux $\left(\mathrm{J}_{\mathrm{sm}}, 0.141\right.$ $\left.(0.06) \mu \mathrm{mol} / \mathrm{cm}^{2} / \mathrm{h} ; \mathrm{n}=13\right) . \mathrm{J}_{\mathrm{sm}}$ was used in subsequent measurements of monolayer permeability. IL-2 treatment had no significant effect at any dose between 2.5 and $40 \mathrm{U} / \mathrm{ml}$ (fig 4B)

IL-2 AND IL-15 RECEPTOR mRNA

Transcripts for $\alpha, \beta$, and $\gamma c$ chains were identified by northern blot analysis in peripheral blood mononuclear cells, as expected (fig 5, control lane). However, BN cells expressed transcripts for $\beta$ and $\gamma_{c}$ but not $\alpha$ chains. This was compared with T84 cells, in lane 3, in which only $\gamma c$ transcripts were expressed. ${ }^{15}$ IL-15 $\alpha$ chain mRNA was not detected (not shown).

TYROSINE PHOSPHORYLATION AND STAT PROTEIN EXPRESSION

IL-2 stimulated tyrosine phosphorylation of multiple protein bands in $\mathrm{BN}$ cells (fig 6) as previously reported for intestinal epithelial cells. ${ }^{15}$ In addition, there was a time dependent increase in expression of JAK1, STAT-1, -3,

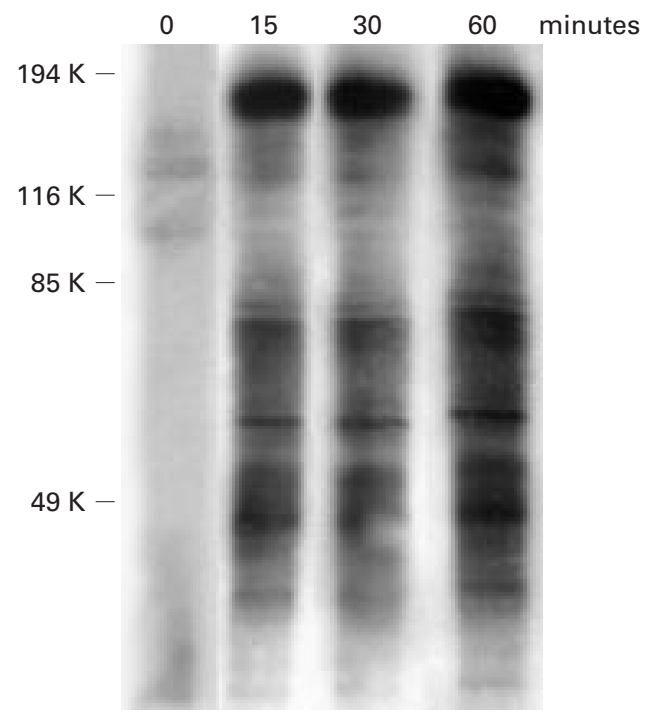

Figure 6 Time dependent tyrosine phosphorylation of proteins in BN cells treated with interleukin 2 (IL-2) 5 U/ml. Numbers on the left indicate molecular weight. Multiple bands of tyrosine phosphorylated proteins were detected by 15 minutes. 


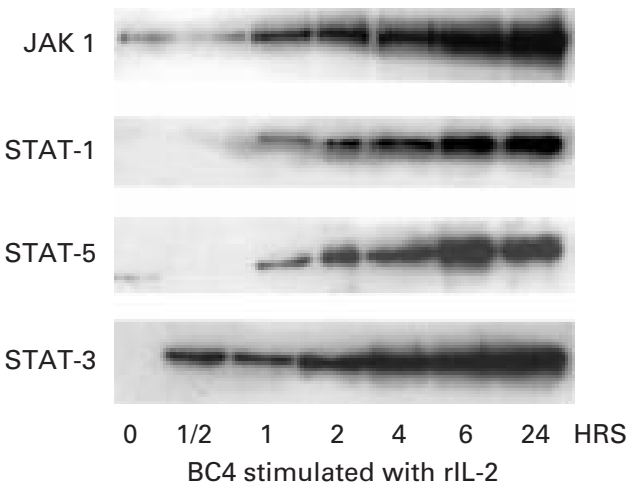

Figure 7 Time dependent increase in expression of janus kinase 1 ( $(\mathcal{F A K} 1)$ and signal transducers and activators of transcription (STAT) $-1,-3$, and -5 in BN cells treated with interleukin 2 (IL-2) $5 \mathrm{U} / \mathrm{ml}$. Cells were treated with IL-2 and lysed at various time points from 0.5 to 24 hours of treatment and proteins detected as described under methods. $I L-2$ treatment increased expression of all proteins from 30 to 60 minutes post incubation.

and -5 which are all involved in signal transduction of IL-2 (fig 7) (reviewed by Gaffen and colleagues ${ }^{26}$ ). Tyrosine phosphorylated proteins appeared within 15 minutes and expression of JAK1 and STAT-3 was increased within 30 minutes of incubation with IL-2, within the time frame of enhancement of secretagogue stimulated secretion.

\section{Discussion}

The results of this study provide evidence that IL-2 modulates ion transport in a small intestinal cell line. Previous investigators have identified functional IL-2 receptor in the intestines of rat and human large intestine and in rat small intestinal and human colon cancer cell lines. ${ }^{1415}$ IL-2 has been shown to modulate epithelial growth in intestinal cell cultures, transforming growth factor $\beta$ gene expression in IEC- 6 cells, and to activate signal transduction pathways via tyrosine phosphorylation in human colon cancer cell cultures. To date, studies have not assessed the effect of IL-2 on epithelial transport. The small intestinal cells utilised in this study express a functional IL-2 receptor which was activated with IL-2 treatment as evidenced by increases in tyrosine phosphorylation and JAK and STAT proteins. Treatment with IL-2 enhanced secretagogue stimulated chloride secretion and stimulated cellular proliferation but did not affect permeability.

We have developed and characterised novel human small intestinal cell lines which grow in polarised monolayers. Some exhibit vectorial transport. ${ }^{16}$ When studied under voltage clamp conditions, these cells exhibit low baseline levels of electrogenic ion transport and when treated with secretagogues such as forskolin develop anion secretion. Incubation of one of the lines, BN, with IL-2 did not alter baseline electrical parameters (that is, electrogenic ion transport) indicating that IL-2 is not a secretagogue. However, low doses of IL-2 caused a $50 \%$ or more increase in secretagogue stimulated chloride secretion. Demonstration that CFTR mRNA is present in BN cells, and our previous observation that secretion could be blocked by the CFTR blocker diphenylamine2-decarboxylate, ${ }^{16}$ suggests that secretion is occurring via CFTR chloride channels. BN cells also exhibit a secretagogue stimulated Isc which is independent of chloride, most likely bicarbonate. ${ }^{17}$ Augmentation of chloride secretory capacity is not specific to IL-2 as IL-15, a cytokine which shares the IL-2R $\beta$ and $\gamma_{c}$ chains and produces similar biological effects to IL-2, ${ }^{19}$ also caused a dose dependent increase in secretagogue stimulated anion secretion. However, treatment of the cells with IL-4 had no effect.

It is not clear from our experiments how IL-2 is increasing the capacity for chloride secretion. The IL-2 effect was mediated via the IL-2R as it was blocked by preincubating the cells with a blocking antibody directed against the IL-2R $\beta$ chain. IL-2 treatment also increased tyrosine phosphorylation ${ }^{15}$ and expression of JAK1 and STAT-1, -3 , and -5 (which are involved in the signal transduction pathway of IL-2 receptor) all within the time frame of the effect on ion transport. If and how these signals modulate secretion is unknown. While interferon $\gamma$ inhibits chloride secretion in T84 cells primarily by inhibition of CFTR gene expression ${ }^{27}$ and the subsequent decrease in apical chloride channels, this mechanism is unlikely to explain the effect on BN cells. Time course studies with the small intestinal cells indicate that the IL- 2 effect occurs by $30 \mathrm{~min}$ utes to two hours after addition to the media, suggesting that the effect is not caused by altered gene expression or new CFTR synthesis. Other investigators have demonstrated that IL-2 can induce an immediate increase in potassium secretion when applied to the surface of macrophages. ${ }^{28}$ This is also not likely to explain our results as IL-2 failed to alter baseline electrical parameters. The data imply that IL-2 is affecting the secretory apparatus, for example by insertion of more CFTR into the apical membrane or altering ionic gradients driving chloride efflux, without affecting secretion per se.

The observations are in keeping with other reports of cytokine modulation of epithelial transport. IL-1 and IL-3 stimulate chloride secretion in chicken intestine ${ }^{29}$ via cyclooxygenase dependent mechanisms. IL-1 treatment in an epithelial-subepithelial myofibroblast coculture model $^{30}$ also enhanced epithelial responsiveness to secretagogues via myofibroblast secretion of arachidonic acid metabolites such as prostaglandin $\mathrm{E}_{2}$. In another study, Madsen and colleagues ${ }^{31}$ demonstrated that IL-10 increased sodium and chloride absorption in vitro in rat small intestine and attenuated secretagogue induced chloride secretion. The same investigators observed that IL-10 treatment reduced chloride secretion and inhibited the cytokine induced increase in epithelial inulin permeability in T84 cells. ${ }^{32}$ Recent reports provide additional evidence that inflammatory mediators may reduce mucosal fluid and electrolyte secretion. ${ }^{33}$ Mucosal hyporesponsiveness to secretagogues has been observed in animal models of TNBS colitis. Increased production of nitric oxide in the inflamed mucosa 
accounted for this inhibition of mucosal secretion. Several other interleukin receptors, including IL-4, $-7,-9$, and -15 , have been identified on human intestinal epithelial cells. ${ }^{15}{ }^{35}$ Treatment of the cells with these cytokines stimulates signal transduction pathways suggesting a physiological role, although functional studies have not determined the role these cytokines may play. Moreover, IL-15, which shares a common $\gamma$ chain with IL-2, modulates transepithelial resistance in T84 monolayers ${ }^{35}$ and induces a similar effect on transport in our small intestinal cells as we reported here for IL-2. Taken together, the available data suggest that the cytokine network can play a role in modulating epithelial transport.

In contrast with the ion transport changes, IL-2 did not affect monolayer permeability, as has been described for some cytokines such as interferon $\gamma$ and tumour necrosis factor $\alpha .^{1135-37}$ IL-2 treatment stimulated cellular proliferation, consistent with previous observations. ${ }^{14}{ }^{15}$ Ciacci and colleagues ${ }^{14}$ observed a biphasic effect of IL-2 on cellular growth in rat IEC-6 cells. Treatment with 10 and $100 \mathrm{U} / \mathrm{ml} \mathrm{stimu-}$ lated proliferation at 24 hours but the higher dose caused growth inhibition at 48 hours. BN cells exhibited proliferation at lower levels, less than $1 \mathrm{U} / \mathrm{ml}$. The differences in the studies could be due to the relative amounts of IL-2R $\beta$ and IL-2R $\gamma \mathrm{c}$ expressed on rat and human cells. While we have not studied the differential surface expression of the various IL-2R chains and their relative binding affinities, such studies have been carried out on human lymphoid cells. ${ }^{38}{ }^{39} \mathrm{CD}^{+} \mathrm{T}$ cells and natural killer cells expressed high levels of IL-2R $\beta$ but very little IL-2R $\alpha$, while $C D 4^{+} T$ cells expressed very low amounts of IL-2R $\beta$. Furthermore, differential expression of these two IL-2R subunits on $\mathrm{CD}^{+}$and $\mathrm{CD} 8^{+} \mathrm{T}$ cells accounted for the differences in IL-2 responsiveness because $\beta \gamma$ constituted the functional receptor. ${ }^{40}$ The combination of $\beta$ and $\gamma$ chains is required for signal transduction ${ }^{42}$ and the proliferative response, and both $\beta$ and $\gamma$ chains were present in our cell line. The $\alpha$ chain which provides a high affinity ligand for IL-2 does not appear to be essential for the proliferative effect and could not be identified in our small intestinal cells, consistent with previous reports. ${ }^{14} 42$ Interestingly, the dose required in our studies to elicit cellular proliferation was considerably less than that required for stimulation of chloride secretion, suggesting that the two biological effects are elicited by different cellular mechanisms. This effect on epithelial cell proliferation may play an important role in maintaining mucosal integrity in intestinal inflammation.

In conclusion, IL-2 was formerly considered to be a cytokine primarily involved in stimulating the growth of lymphocytes, macrophages, and other immunocytes. Functional IL-2R and an effect of IL-2 on epithelial cell proliferation has been demonstrated in several different cell types. This study provides additional evidence for a role of IL-2 in modulating epithelial function. Rather than stimulating ion secretion per se, IL-2 treatment increases the maximal secretory capacity of human small intestinal enterocytes in response to known secretagogues. The data imply a possible role for IL-2 in modulating enterocyte proliferation and amplifying cellular secretion in some inflammatory disorders of the intestine.

Grant support funded by the National Health and Medical Research Council of Australia.

1 Powell DW. Immunophysiology of intestinal electrolyte disorders. In: Field M, Frizzell RA, eds. Handbook of physiology. Section 6 The gastrointestinal system, vol IV. Intestinal absorption and secretion. Bethesda, Maryland: American Physiological Society, 1991:591-641.

2 Perdue MH, Gall DG. Intestinal anaphylaxis in the rat: jejunal response to in vitro antigen exposure. Am $\mathcal{F}$ Physiol 1986;250:G427-31.

3 Perdue MH, Chung M, Gall DG. Effect of intestinal anaphylaxis on gut function in the rat. Gastroenterology 1984;86:391-7.

4 Catto-Smith AG, Patrick MK, Hardin JA, et al. Intestinal anaphylaxis in the rat: mediators responsible for the ion transport abnormalities. Agents Actions 1989;28:185-91.

5 Castro GA, Harari Y, Russell D. Mediators of anaphylaxis induced ion transport changes in small intestine. Am $\mathcal{F}$ Physiol 1987;253:G540-8.

6 Perdue MH, Masson S, Wershil BK, et al. Role of mast cell in ion transport abnormalities associated with intestinal anaphylaxis. Correction of the diminished secretory response in genetically mast cell-deficient W/Wv mice by bone marrow transplantation. I Clin Invest 1991;87:68793.

7 Kelly CP, Becker S, Linevsky JK, et al. Neutrophil recruitment in Clostridium difficile toxin A enteritis in the rabbit. F Clin Invest 1994;93:1257-65.

8 Elliott E, Li Z, Bell C, et al. Modulation of host response to Escherichia coli 0157:H7 infection by anti-CD 18 antibody in rabbits. Gastroenterology 1994;106:1554-61.

9 Madara JL, Parkos C, Colgan S, et al. Cl- secretion in a model intestinal epithelium induced by a neutrophilmodel intestinal epithelium induced by a neutroph
derived secretagogue. 7 Clin Invest 1992;89:1938-44.

10 Madara JL, Patapoff TW, Gillece-Castro B, et al. 5'Adenosine monophosphate in the neutrophil derived paracrine factor that elicits chloride secretion from T84 intestina epithelial cell monolayers. F Clin Invest 1993;91:2320-5.

11 McKay DM, Croitoru K, Perdue MH. T cell-monocyte interactions regulate epithelial physiology in a coculture model of inflammation. Am F Physiol 1996;270:C418-28.

12 Boismenu R, Havran WL. Modulation of epithelial cell growth by intraepithelial gamma $\delta$ T cells. Science 1994; 266:1253-5.

13 da Cunha Ferreira R, Forsyth LE, Richman PI, et al. Changes in the rate of crypt epithelial cell proliferation and mucosal morphology induced by a $\mathrm{T}$ cell mediated response in human small intestine. Gastroenterology 1990; 98:1255-63.

14 Ciacci C, Mahida YR, Dignas A, et al. Functional interleukin 2 receptors on intestinal epithelial cells. $\mathcal{F}$ Clin Invest $1993 \cdot 92 \cdot 527-32$

15 Reinecker H-C, Podolsky DK. Human intestinal epithelial cells express functional cytokine receptors sharing the common gamma c chain of the interleukin 2 receptor. Proc Natl Acad Sci USA 1995;92:8353-7.

16 Pang G, Buret A, O'Loughlin E, et al. Immunological, functional and morphological characterisation of three new human small intestinal epithelial cell lines. Gastroenterology 1996;111:8-18

17 Smith JJ, Welsh MJ. cAMP stimulates bicarbonate secretion across normal but not cystic fibrosis airway epithelia. $\mathcal{F}$ Clin Invest 1992;89:1148-53.

18 O'Loughlin EV, Hunt DM, Kreutzmann D. Postnatal development of colonic electrolyte transport. Am F Physiol 1990; 258:G447-53.

19 Kennedy MK, Park LS, Paxton RJ. Interleukin-15 . In: Thompson AW, ed. The cytokine handbook, 3rd edn. San Diego: Academic Press, 1998:443-64.

20 O'Loughlin E, Winter M, Shun A, et al. Structural and functional adaptation following jejunal resection in rabbits: Effect of epidermal growth factor. Gastroenterology 1994; Effect of epide

21 Ciacci C, Mahida YR, Dignass A, et al. Functional interleukin-2 receptors on intestinal epithelial cells. $\mathcal{F}$ Clin Invest 1993;92:527-32.

22 Arcari P, Martinelli R, Salvatore F. The complete sequence of a full length CDNA for human liver glyceraldehyde-3phosphate dehydrogenase: evidence for multiple mRNA species. Nucleic Acids Res 1984;12:9179-89.

23 Montrose Rafizadeh C, Blackmon DL, Hamosh A, et al. Regulation of cystic fibrosis transmembrane conductance regulator (CFTR) gene transcription and alternative RNA splicing in a model of developing small intestinal epithelium. f Biol Chem 1992;267:19299-305.

24 Cartwright CA, McRoberts JA, Mandel KG, et al. Synergistic action of cyclic adenosine monophosphate and calcium mediated chloride secretion in a colonic epithelial cell line. mediated chloride secretion in

F Clin Invest 1985;76:1837-42.
25 Anderson MP, Sheppard DN, Berger HA, et al. Chloride channels in the apical membrane of normal and cystic channels in the apical membrane of normal and cystic
fibrosis airway and intestinal epithelia. Am $f$ Physiol 1992;263:L1-14. 
26 Gaffen SL, Goldsmith MA, Green WC. Interleukin-2 and the interleukin-2 receptor. In: Thompson AW, ed. The cytokine handbook, 3rd edn. San Diego: Academic Press, 1998: 73-103.

27 Besancon F, Przewlocki G, Baro I, et al. Interferon-gamma downregulates CFTR gene expression in epithelial cells. Am f Physiol 1994;267:C1398-404

28 Marin DK, Bootcov MR, Campbell TJ, et al. Human macrophages contain a stretch-sensitive potassium channel that is activated by adherence and cytokines. $7 \mathrm{Membr}$ Biol 1995; 147:305-15.

29 Chang EB, Musch MW, Mayer L. Interleukins 1 and 3 stimulate anion secretion in chicken intestine. Gastroenterol ogy 1990;98:1518-24.

30 Hinterleitner TA, Saada JL, Berschneider HM, et al. IL-1 stimulates intestinal myofibroblast COX gene expression and augments activation of Cl- secretion in T84 cells. Am $\mathcal{F}$ Physiol 1996;271: C1262-8.

31 Madsen KL, Tavernini MM, Mosmann TR, et al. Interleukin 10 modulates ion transport in rat small Interleukin 10 modulates ion transport

32 Madsen KL, Lewis SA, Tavernini MM, et al. Interleukin 10 prevents cytokine-induced disruption of T84 monolayer barrier integrity and limits chloride secretion. Gastroenterology 1997;113:151-9.

33 MacNaughton WK, Lowe SS, Cushing K. Role of nitric oxide in inflammation induced suppression of secretion in a mouse model of acute colitis. Am f Physiol 1998;275: G1353-60.
34 Asfaha S, Bell CJ, Wallace JL, et al. Prolonged colonic epithelial hyporesponsiveness after colitis: role of inducible

35 Stevens AC, Matthews J, Andres P, et al. Interleukin-15 signals T84 colonic epithelial cells in the absence of the interleukin-2 receptor $\beta$-chain. Am f Physiol 1997;272: G1201-8.

36 Madara JL, Stafford J. Interferon-gamma directly affects barrier function of cultured intestinal epithelial monolayers. F Clin Invest 1989;83:724-7.

37 Adams RB, Planchon SM, Roche JK. IFN- $\gamma$ modulation of epithelial barrier function. Time course, reversibility and site of cytokine binding. F Immunol 1993;150:2356-63.

38 Ohashi Y, Takeshita T, Nagata K, et al. Differential expression of the IL-2 receptor subunits, p55 and p 75 on various populations of primary peripheral blood mononuclear cells. F Immunol 1989;143:3548-55.

39 Ishii N, Takeshita T, Kimura Y, et al. Expression of the IL-2 receptor gamma chain on various populations in human peripheral blood. Int Immunol 1994;6:1273-7

40 Yagita H, Nakata M, Azuma A, et al. Activation of peripheral blood T cells via the p 75 interleukin 2 receptor. peripheral blood T cells via the

41 Nakarai T, Robertson MJ, Streuli M, et al. Interleukin receptor gamma chain expression on resting and activated lymphoid cells. F Exp Med 1994;180:241-51.

42 Nakamura Y, Russell SM, Mess SA, et al. Heterodimerization of the IL- 2 receptor $\beta$ - and gamma chain cytoplasmic domains is required for signalling. Nature 1994;369:330-3.

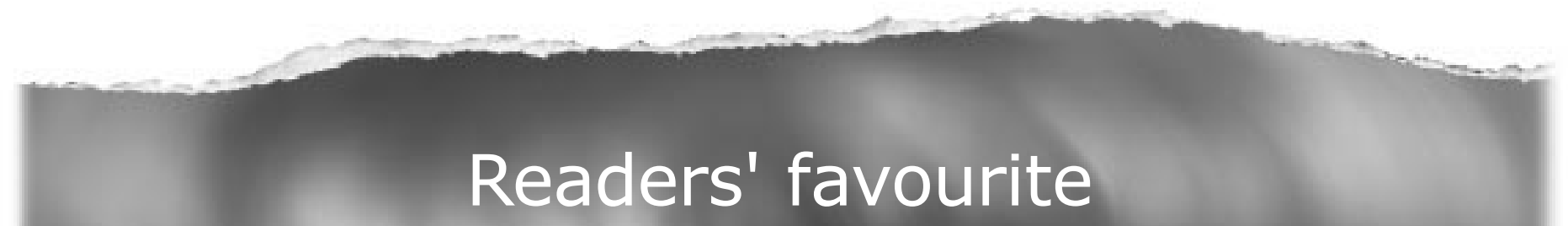

Top 10

Click on the "Top 10" button on the homepage to see which are the best read articles each month

www.gutjnl.com 